\title{
A SUSTENTÁVEL SIGNIFICAÇÃO DO SER
}

\section{João Bosco Figueiredo Gomes ${ }^{\star}$}

Resumo: O artigo, colocando em discussão a visāo tradicional do verbo ser, apresenta uma breve análise dos seus diferentes usos. Utiliza dados de textos reais do dialeto de Fortaleza/CE. Os resultados tendem a evidenciar a hipótese de um percurso de gramaticalização, segundo o qual os significados/funçōes do verbo ser partem do concreto ao abstrato.

Palavras-chave: Gramaticalização. Verbo. Interação

\section{Introdução}

A gramática tradicional classifica o verbo ser ou como verbo existencial, por conseguinte, intransitivo; ou como verbo auxiliar, em locuçōes verbais; ou como "verbo de ligação", "cópula", "relacional", "de estado", um verbo vazio de significado, que expressa tão somente as categorias tempo, modo e, para alguns, aspecto, e que tem a função de ligar e relacionar dois elementos: sujeito e predicado.

Os estudos existentes sobre o verbo ser são obscurecidos pela dificuldade de se propor uma definição satisfatória da natureza e das funções desse verbo. Geralmente, as propostas teóricas ${ }^{1}$ centram-se mais nos aspectos morfológico e sintático; menos no semântico, referindo-se apenas ao esvaziamento e à carência de transitividade; e, menos ainda, ao discursivo. Objetivamos, portanto, a partir de produçōes reais de usuários, à guisa de um

- Professor-Adjunto de Lingüística da Universidade do Estado do Rio Grande do Norte (UERN) e doutorando do Programa de Pós-graduação em Lingüística da Universidade Federal do Ceará (UFC).

1 O esvaziamento semântico, a noção de aspecto e a centralidade do verbo ser; um ou outros, já podem ser vistos diferentemente em Mira Mateus et al. (1983), Brito (1986), Vilela (1992) e Borba (1996). 
estudo piloto, levantar os contextos/funções do ser, observando os quatro aspectos acima mencionados, para verificar que processo(s)/ mecanismo(s) explica(m) os diferentes usos do verbo ser na modalidade oral.

Para tanto, adotamos uma perspectiva funcionalista que coloca em evidência a noção de domínio funcional complexo, resultante da interação de motivações cognitivas, comunicativas e estruturais. Orientamo-nos, principalmente, pelas propostas de Heine et al. (1991), Traugott e König (1991), Hopper \& Traugott (1993), Tragott (1995), Givón (1995) e Martelotta et al. (1996); além de nos basear nos pressupostos teóricos de Lakoff (1980 e 1987), Johnson (1987), e Sweetser (1990). Acreditamos que o paradigma da gramaticalização é capaz de explicar o processo de mudança por que passa(ra)m os diferentes usos do verbo ser.

Nossa amostra se constitui de 427 ocorrências do verbo ser em 120 minutos de fala (não-culta) de 04 informantes (Diálogo entre Informante e Documentador - DID) do corpus A lingua falada em Fortaleza, organizado por Aragão \& Soares (1996), estratificados de acordo com a escolaridade: 01 da quarta série $(\mathbf{Q})$ e 01 da oitava série $(\mathbf{O})$ do Ensino Fundamental, 01 da terceira série $(\mathbb{T})$ do Ensino Médio, e 01 analfabeto (A), com 66, 95, 127e 139 ocorrências, respectivamente. Descrevemos os dados a partir de uma análise quantitativa, com cálculo de freqüência, cruzamentos de dados e tratamento estatístico, utilizando o programa Statistical Package for the Social Sciences - SPSS; e de uma análise qualitativa, visando explicar o fenômeno em questão.

O artigo está organizado da seguinte maneira: primeiramente, apresentamos a nossa concepção de língua e de gramática; depois, abordamos sobre a relação gramaticalização e cognição; e, por último, a análise dos diferentes usos do verbo ser. 


\section{Concepção de língua e gramática}

Du Bois (1985) considera a gramática como um sistema adaptativo em que forças motivadoras dos fenômenos externos penetram no domínio da língua e passam a interagir com forças organizadoras internas, competindo e conciliando-se sistematicamente com elas. Deriva daí o fenômeno da gramaticalização, que pode ser visto como a evolução de construções relativamente livres no discurso, motivadas por necessidades comunicativas, para construções relativamente fixas na gramática. Podemos perceber, então, nesse processo, a idéia de continuum em que, num pólo, temos construçōes mais frouxas e, no outro, construções mais fixas.

Para Du Bois (1987), a relação entre discurso (ou uso, portanto, pragmático) e gramática pode ser equacionada da seguinte maneira: i) a gramática molda o discurso e ii) o discurso molda a gramática. Podemos ler ainda sobre essa via de duas mãos que: "a gramática é feita à imagem do discurso"; porém, na verdade, na outra mão, "o discurso nunca é observado sem a roupagem da gramática" (1987, p. 11).

Dentro da visão de motivações em competição, Givón (1995, p. 09) elenca algumas premissas funcionalistas que devem ser circunscritas por princípios (em competição) que interagem e restringem sua aplicabilidade, a saber: a) a linguagem é uma atividade sócio-cultural (uso da língua na comunicação); b) a estrutura serve a uma função cognitiva (processamento mental) ou comunicativa (interação) - há uma relação, de duas māos, forma e funçāo; c) a estrutura é não-arbitrária, motivada, icônica (idealizada); d) a mudança e a variação estão sempre presentes; e) as categorias não são discretas (há um continuum, que sugere uma escalaridade); f) a estrutura ć maleável, não rígida, modelada por pressões externas (do contexto extralingüístico - sócio-cultural, situacional e discursivo) e por pressōes internas (do co-texto, sistema propriamente lingiístico); e g) as gramáticas são emergentes (nunca se estabilizam). 
Givón, então, parte do pressuposto de que a gramática é um fenômeno emergente, que surge de necessidades comunicativas, e que deve ser interpretada como: i) instruçōes de processamento mental - do falante para o ouvinte (1991, p.7), isto é, parte do complexo mapeamento entre pensamento e fala (1995, p. 305); ii) conjunto de estratégias empregadas para se produzir uma comunicação coerente; e iii) no seu contexto discursivo ("no" texto).

Assim, a gramática é entendida como um sistema formado pelas regularidades resultantes das pressōes de uso. Segundo Martelotta et al. (1996), essas pressões, que estão relacionadas a um complexo de interesses e necessidades discursivas/pragmáticas fundamentais, podem compreender: a) os propósitos comunicativos do falante em ser expressivo e informativo; b) ou o fenômeno da existência de lacunas nos paradigmas gramaticais ou no universo de conceitos abstratos. Então, novas estruturas gramaticais se desenvolvem motivadas por necessidades comunicativas não preenchidas ou pela emergência de conteúdos cognitivos para os quais não existem designações lingüísticas adequadas.

\section{Gramaticalização e cognição}

Associado à concepção de gramática como estrutura maleável, emergente, o conceito de gramaticalização pode ser considerado como um processo especial de mudança lingüística.

Para Furtado da Cunha (1996), a "gramaticalização" tem dois sentidos: o de paradigma e o de processo. No primeiro sentido, a gramaticalização focaliza como as formas e construções gramaticais surgem, como são usadas e como modelam a língua. Dessa maneira, o paradigma de gramaticalização diz respeito à interdependência entre estrutura e uso, buscando, pois, descrever e explicar, concomitantemente, um tipo especial de variação/mudança lingüística e o grau de desgaste/ manutenção das formas que mudam. Com o sentido de processo, a gramaticalização se refere aos processos pelos quais os itens se tornam 
mais gramaticais ao longo do tempo. Assim, a gramaticalização é (dúvida) um processo diacrônico e um continuum sincrônico que atinge $(\mathrm{m})$ tanto as formas que vão do léxico para a gramática como as formas que mudam no interior da gramática. Trata-se, então, de um processo lingüístico de organização de categorias e de codificação que pode ser estudado tanto através do tempo quanto sincronicamente.

Bybee et al. (1994, p. 298) tendem a uma abordagem mais pragmática, ao estudar a gramaticalização, salientando que a relação entre estrutura e função é mediada pela diacronia. Afırmam que a relação entre gramática e função é indireta, pois os processos, como a metáfora e a inferência, que conduzem a gramaticalização, ocorrem na língua em uso e são impulsionados pela necessidade de se (re)interpretar itens no contexto (para eles, é o uso da língua que modela o significado dos morfemas gramaticais). Assim, a natureza sistemática do desenvolvimento da gramática pode ser atribuída à natureza sistemática dos processos mentais e comunicativos que governam o uso da língua.

Traugott (1995, p. 3), também interessada por fenômenos relacionados à mudança lingüística, passou a adotar o paradigma da gramaticalização, focalizando os aspectos semântico-pragmáticos da mudança. A autora localiza o componente pragmático nos estágios iniciais da gramaticalização, que pode ser fortalecido, especialmente, no que se refere ao acréscimo do envolvimento e da expressividade subjetiva do falante em termos de atitudes e crenças. Dessa forma, ela adota uma visão alargada de gramática que adiciona à fonologia, à morfossintaxe e à semântica certos aspectos comunicativos e pragmáticos. Deriva daí também a ampliação da definição de gramaticalização, vista como o "processo pelo qual um item lexical, impulsionado por um certo contexto pragmático e morfossintático, torna-se gramatical" (TRAUGOTT, 1995, p. 1).

Acolhemos a idéia de que essa trajetória de mudança ocorre pela atuação gradual de processos/mecanismos de natureza metafórica e de natureza metonímica, em que os significados, na dependência do contexto, migram de funções mais concretas e mais dêiticas para funções mais abstratas e relacionais. 


\section{Os diferentes usos do verbo ser}

Bréal (1992) afirma que não há dúvida de que o verbo ser começou com uma mera significação concreta. É corroborado por Brugman (1905 apud Guérios, s/d, p. 09) que afirma que o verbo ser era primitivamente um verbo com significação concreta (do lat. esse) e o sentido mais antigo que se pode firmar é "existir", sentido este admitido por Meillet (1924) e, igualmente, por Vendryés (1921)². Este último afirma que a raiz proto-indo-européia es (ser), que forneceu a cópula em data muito antiga, denota propriamente "a existência, a vida", e o demonstra através do particípio sat, que designa um ser real, e o derivado satyas, "verdadeiro", e mediante o grego tà ónta, "a realidade". Said Ali (1966, p. 197) afirma que o sentido existencial de ser, cujos vestígios ainda se conservam em frase como "era uma vez...", "obliterou-se completamente, e de longa data, nas combinações com adjetivo ou substantivo".

Dada a produtividade do verbo ser na língua portuguesa, questionamos essa "obliteração" e propomos analisar o verbo ser como uma palavra polissêmica. Por polissemia, entendemos o processo que se refere a funçōes diferentes para a mesma forma, ou seja, "as unidades polissêmicas são derivadas de uma mesma fonte, sendo resultado de processos de extensão como a metáfora e a metonímia" (CROFT \& CRUISE, 2004, p. 111). Advogamos que a forma mais antiga não é necessariamente descartada, podendo interagir com as novas funções.

A Tabela 1 apresenta um resumo da quantidade de ocorrências dos tipos de significados/funções do verbo ser, encontrados em nossa amostra, relacionados ao grau de escolaridade dos informantes ${ }^{3}$.

Os dois autores sảo citados em Guérios (s/d, p. 09).

O fator escolaridade foi aqui considerado em virtude da organização do corpus. Mas, neste momento, não iremos considerar esse fator na análise. 
Tabela 1: Significados/funções do verbo ser $\mathrm{x}$ Escolaridade ${ }^{4}$

\begin{tabular}{|l|l|c|cc|c|c|}
\hline \multicolumn{2}{|c|}{\begin{tabular}{c} 
Escolaridade \\
\multicolumn{2}{|c|}{ Significado/Função }
\end{tabular}} & \multicolumn{1}{|c|}{ A } & Q & 0 & T & TOTAL \\
\hline 01 & Existir & $1 / 16,7 \%$ & $4 / 66,4 \%$ & $1 / 16,7 \%$ & - & $6 / 1,4 \%$ \\
\hline 02 & Acontecer & $7 / 41,2 \%$ & $3 / 17,6 \%$ & $3 / 17,6 \%$ & $4 / 23,4 \%$ & $17 / 4 \%$ \\
\hline 03 & Ficar; Situar-se & $3 / 50 \%$ & $2 / 33,3 \%$ & - & $1 / 16,7$ & $6 / 1,4 \%$ \\
\hline 04 & Indicar tempo ou época & $9 / 50 \%$ & $1 / 5,6 \%$ & $2 / 11,1 \%$ & $6 / 33,3 \%$ & $18 / 4,2 \%$ \\
\hline 05 & Interessar; Dizer respeito & $3 / 100 \%$ & - & - & - & $3 / 0,7 \%$ \\
\hline 06 & Consistir em & $3 / 37,5 \%$ & - & $1 / 12,5 \%$ & $4 / 50 \%$ & $8 / 1,9 \%$ \\
\hline 07 & Provir; Pertencer & $5 / 26,3 \%$ & $5 / 26,3 \%$ & $3 / 15,8 \%$ & $6 / 31,6 \%$ & $19 / 4,4 \%$ \\
\hline 08 & Ter a profissão, o cargo & $6 / 46,2 \%$ & $1 / 7,7 \%$ & $3 / 23,1 \%$ & $3 / 23,1 \%$ & $13 / 3 \%$ \\
\hline 10 & Caracterizador & $43 / 36,8 \%$ & $17 / 14,5 \%$ & $20 / 17,1 \%$ & $3731,6 \%$ & $117 / 27,4 \%$ \\
\hline 11 & Identificador & $29 / 33 \%$ & $13 / 14,8 \%$ & $23 / 26,1 \%$ & $23 / 26,1 \%$ & $88 / 20,6 \%$ \\
\hline 12 & Auxiliar & $4 / 100 \%$ & - & - & - & $4 / 0,9 \%$ \\
\hline 13 & Marcador de Afirmação & $5 / 8,2 \%$ & $14 / 23 \%$ & $25 / 41 \%$ & $17 / 27,9 \%$ & $61 / 14,3 \%$ \\
\hline 14 & Marcador de foco(ser que) & $13 / 48,1 \%$ & $1 / 3,7 \%$ & $6 / 22,2 \%$ & $7 / 25,9 \%$ & $27 / 6,3 \%$ \\
\hline 15 & Marcador de foco(ser) & $7 / 31,8 \%$ & $4 / 18,2$ & $2 / 9,1$ & $9 / 40,9$ & $22 / 5,2 \%$ \\
\hline 16 & Preenchedor de Pausa & $1 / 5,6 \%$ & $1 / 5,6 \%$ & $6 / 33,3 \%$ & $10 / 55,6 \%$ & $18 / 4,2 \%$ \\
\hline & TOTAL & $139 / 32,5 \%$ & $66 / 15,5 \%$ & $95 / 22,2$ & $127 / 29,8 \%$ & 427 \\
\hline
\end{tabular}

Dentre os vários significados/funções constantes da Tabela 1 , podemos observar que o ser caracterizador e o identificador são os tipos mais freqüientes, com $27,4 \%$ e $20,6 \%$, respectivamente. Os dois juntos são exemplos do tipo tradicionalmente conhecido como verbo de ligação (ver mais adiante exemplos 10 e 11). Depois, temos como mais freqüientes os marcadores: o de afirmação, com 14,3\%, e o de foco, com 11,5\% (ver exemplos 13 e 14-15).

Doravante utilizaremos "ser", generalizando os usos desse item lexical, uma vez que, a partir do tipo 13 , ele deixa de ser verbo. 
A partir do levantamento das significações/funções do ser, sob o controle dos aspectos morfológicos, sintáticos, semânticos e pragmático-discursivos ${ }^{5}$, acreditamos ter encontrado o caminho para explicar a natureza e funções deste item lexical. Analisemos, pois, as 16 unidades polissêmicas derivadas do ser significando existir, como ainda o encontramos no português contemporâneo, exemplificado em (1a-b):

(1) a.

DOC: Uma coleguinha assim que você goste mais dela?

INF: eh: :: são duas, (Q032-006-LFF) ${ }^{6}$

b. ...o Sarney só tá mesmo porque é o presidente' tá dando aquelas ordens' mas Dilson Funaro se não fosse ele' o Sarney acho que iria pela metade só, (O238-058-LFF)

Constatamos que, com esse significado, há uma preferência pelas cláusulas complexas do tipo condicional (com o verbo ser vem no imperfeito do subjuntivo) e temporal, bem como pelas cláusulas simples (geralmente em respostas curtas), ambas com sujeito posposto.

A partir desse significado-fonte, tentamos, por questōes metodológicas, simplificar nossa análise, dividindo as unidades em três blocos nomeados provisoriamente segundo os aspectos

Considerando as limitaçōes de espaço, nāo detalhamos todas as características de cada unidade polissêmica; destacamos apenas as dominantes.

Os exemplos citados foram codificados da seguinte maneira: a letra se refere à escolaridade do informante; os três primeiros números, à linha do corpus escrito; os outros três, à ocorrência. Nos parênteses, está a freqüência de uso da função em questão do verboser conforme a escolaridade, justificando, assim, o número de exemplos. A transcrição dos dados segue as convençōes explicitadas em Aragão e Soares (1996). 
caracterizadores que são mais salientes: Bloco I - aspectos semânticopragmáticos: acontecer; ficar; situar-se; interessar, dizer respeito ou referir-se a, convir; consistir em; provir, pertencer; ter o cargo, pertencer à categoria, ter a profissão; indicar tempo ou época; Bloco II - aspectos morfossintáticos: ser cópula (caracterizador e identificador) e ser auxiliar; e Bloco III aspectos discursivo-pragmáticos: marcador de afirmação; marcador de foco (ser(...)que e ser); e o preenchedor de pausa.

Bloco I - Aspectos semântico-pragmáticos:

a) Acontecer

Pezatti (1992) observa outra função do ser, ao lado de ter, existir, haver, como verbo intransitivo existencial, ou seja, aquele que expressa existência positiva; e o verbo acontecer, também como existencial, que denota emergência de uma entidade. Segundo a concepção de cena cognitiva postulada por Fillmore (1977), o falante, ao selecionar o verbo, já tem em mente o que deseja trazer em cena; então, na opção por um verbo existencial, revela o seu (do falante) desejo de indicar a emergência ou existência positiva de uma entidade.

a. ((falando sobre o assalto $))$

foi no começo da Treze de Maio, (O334-072-LFF)

b.

imitando assim $(+)$ só as figura da cidade' sabe" fazer um show vai ser hoje,

(T337-097-LFF)

Funciona como verbo intransitivo, acompanhado de uma circunstância (modo, lugar e tempo). 
b) Ficar; situar-se

Como verbo expressa estado com duração ilimitada e incompleta e vem acompanhado de circunstância de lugar.

(4) a. num saber onde é o Mercado dos Pião' (T124-045-LFF)

b. DOC: O Papouco é por aqui perto?

INF: é lá atrás, (A136-040-LFF)

Silveira (1980), ao estudar o emprego de sedere (Port.: estar sentado) por esse (Port.: ser), em documentos latinos bárbaros (os termos que neles aparecem constituem o chamado português proto-histórico), observa que esses verbos se equivalem semanticamente e detecta traços que lhes são comuns por ambos os verbos exprimirem um estado que tem continuidade no tempo e não uma ação tomada em determinado instante de seu desenvolvimento. Conclui que tal fato vem explicar o porquê de ter a linguagem popular empregado sedere por esse; c acrescenta que é do parecer de que a fusão, num mesmo paradigma, dos dois verbos deve-se atribuir, em primeiro plano, a sua afinidade semântica e não à semelhança ou à coincidência fonética de suas formas, pois antes de ter se efetuado a coincidência das formas, o verbo sedere era usado em substituição de esse. Tal fusão resultou numa alteração semântica do verbo sedere que, a princípio, significava "estar sentado", e passou a designar, genericamente, "estado". Houve, então, certa atenuação de seu significado; fenômeno que ocorre freqüentemente na linguagem. 
c) Indicar tempo ou época

O verbo ser refere-se à situação que está sendo narrada ou a um sujeito expresso por um nome designativo de evento, e acompanhado de complemento de tempo.

...quando cheguei lá’ $(+)$ foi de manhã ele chegou' com um guarda-chuva

na cabeça, aí quando foi de manhã’ foram buscar o CORpo' ...

(A268-075-LFF)

d) Interessar; dizer respeito ou referir-se a; convir

Evidenciamos o significado de interessar; dizer respeito ou referirse a; convir devido ao contexto em que a informante analfabeta (A) descreve as benfeitorias do bairro realizadas pelo Padre Batista. Ao usar a construção tudo é o Padre Batista, a informante teve a intenção de enunciar "tudo é com o Padre Batista", contudo dispensou o uso da preposição "com", própria de uma construção de linguagem mais formal para o sentido pretendido.

filha, tudo aqui, TOda a doença, e tudo $(+)$ é o Padre Batista, $(+)$ é o Padre Batista, ninguém tem pra onde correr, (A112-031-LFF)
e) Consistir em 
Como verbo, o ser tem a preferência à sua direita por infinitivo ou oração infinitiva bem como por oração desenvolvida iniciada pela integrante "que".

a minha vida aqui é::é fazer a caridade, $(+)$ é correr' levar um doente pro hospital' tá doente' CORre' chega mais' chama ali a Dona Fransquinha' leva pro hospital' passa a noite' (A297-098-LFF)

f) Provir; pertencer

O verbo ser vem com complemento de origem, através de sintagma preposicionado.

(8) a. INF: eu só sei' que foi começando com papoca' foi crescendo' foi crescendo' papoca de pus,

DOC: E aí?

INF: ai a mãe' minha mãe levava eu pro médico' o médico dizia que era da cama' dizia que era da água' dizia que era do sabonete' (Q183-032-LFF)

b. não mestra' não gosto de reclamar dela não' porque ela é de um partido pobre e bem pequenininho (R184-041-LFF)

g) Ter o cargo, ter a profissão, pertencer à categoria

O ser com o significando ter o cargo, ter a profissão, pertencer à categoria poderia ser parte da subdivisão "identificador" que nós 
propusemos para "o ser cópula" mais adiante, uma vez que, como verbo, carrega as características do "identificador". Preferimos colocá-lo com um sentido à parte por ele ser muito produtivo no contexto sócio-cultural, em que as pessoas valorizam ou identificam as outras pela profissão. É comum na nossa sociedade a pergunta: O que ele(a) é? e a resposta, de imediato, reporta-se à profissão, caso a pergunta não seja empregada num contexto específico. Trata-se, portanto, de uma convencionalização por implicatura conversacional.

(9) DOC: E qual é o trabalho do seu pai? O pai mesmo, que né o avô.

INF: $\quad$ Sim' ele é gerente do Mercantil Saionara' lá no bairro da Maraponga (O095-018-LFF)

Observamos, na seqüência dos significados, uma certa gradiência na passagem de verbo pleno a verbo funcional cópula. Primeiramente, os significados se dão por inferência metafórica e metonímica, no que diz respeito às noções de ESPAÇO (existir, acontecer, provir, cargo) e TEMPO (indicar tempo, acontecer, ficar) em contigüidade sintática com complemento de lugar, origem, tempo e modo, além da convencionalização por implicatura conversacional.

Bloco II - Aspectos morfossintáticos:

a) Ser cópula

Acreditamos na trajetória do ser como cópula como se encaminhando do sentido mais concreto para o mais abstrato, ou seja, do léxico para a gramática. Assim, o ser sofre uma atenuação semântica e passa a assumir, em certos contextos, funções gramaticais. 
Concebemos o ser cópula como um elemento central da frase. Chafe (1979) supõe que o universo conceptual humano compreende duas grandes áreas: uma central, a do verbo, que engloba estados (condições, qualidades) e eventos; outra periférica, a do nome, que engloba "coisas" (tanto objetos físicos como abstraçōes coisificadas) ${ }^{7}$. A natureza do verbo é que determina quantos e quais serão os nomes e como será sua relação com eles.

Como verbo de estado, o ser cópula expressa um certo estado ou condição a um sintagma nominal na função sintática de sujeito que, por sua vez, é especificado por uma característica (10) ou uma identificação (11), com função sintática de predicativo, que complementa o significado do verbo.

\section{a.1) Caracterizador}

(10) mas os professores são ótimo’ tem alguns bons, (T015-007-LFF)
a.2) Identificador

(11) Cangaceiro Trapalhão, porque Lampião num é um cangaceiro" (O167-034-LFF)

Sobre a significação do ser cópula, amplamente reconhecido como vazio de significado, temos a hipótese de que o significado original de ser como existir persiste na cópula tanto identificadora (ex.: O lampião é[= existe como $]$ um cangaceiro) como caracterizadora (ex.: O professor é [ = existe como, na qualidade de] ótimo), daí exprimir estado duradouro.

Chafe(1979) usa os termos semânticos "verbo" e "nome" que, segundo ele, podem ser empregados como "predicado" e "argumento" respectivamente. 
b) Verbo auxiliar

O ser como verbo auxiliar evidencia a consolidação do processo de gramaticalização que consiste na mudança de itens da classe dos verbos plenos para a classe dos verbos auxiliares. Assim, o ser forma uma locução com o segundo verbo, apresentando-lhe categorias gramaticais (número, pessoa, tempo, modo e aspecto). O verbo ser + particípio formam a voz passiva de ação.

(12) todo o melho/ tudo que tem aqui dentro feito' foi feito pelo Padre Batista, (A137-042-LFF)

Bloco III - Aspectos discursivo-pragmáticos:

a) Marcador de afirmação

Figueiredo-Gomes (1999) assume que a trajetória do ser como afirmação tem como ponto de partida a gramaticalização da alorepetição da cópula. Hipotetizamos que a repetição funciona no apagamento de constituintes: primeiramente, à esquerda, e depois, à direita, ficando, depois da elisão das informações redundantes, apenas o ser para assegurar a afirmação da seqüência anterior. Dessa maneira, a repetição recategoriza a classe do verbo enquanto cópula, dando origem a uma sentença que assume um papel funcional de afirmar, ou seja, igual a um sim. Respeitando o princípio de iconicidade ${ }^{8}$ em sua formulação branda (GIVÓN, 1995), segundo

Segundo esse princípio, em sua versão forte, há, na codificação lingïística, a relação motivada de um-para-um entre expressão/forma e conteúdo, cm situação oposta à arbitrariedade. Essa relação é assimétrica, uma vez que o conteúdo determina a forma, e não vice-versa. 
o qual a relação entre expressão/forma e conteúdo se insere num continuum entre os pólos transparência semântica e opacidade; e postulando a unidirecionalidade da mudança, no sentido da abstratização progressiva do significado, o ser afirmação, uma vez gramaticalizado, responde afirmativamente à primeira seqüência do par conversacional em que não há sua ocorrência, mas atendendo às restrições gramaticais do verbo dessa seqüência. Depois, continuando a possível trajetória, o ser afirmação, sem atender às restrições gramaticais do verbo da seqüência anterior, cristaliza-se (como fórmula) na $3^{2}$. pessoa singular do indicativo é e, mais radicalmente, discursiviza-se ${ }^{9}$, ou seja, assume restrições de caráter pragmático e interativo, passando a funcionar como um marcador de retroalimentação conversacional - MRC de afirmação. Então, por meio do processo de gramaticalização e discursivização, o ser tende a seguir uma trajetória, partindo do sentido mais concreto para o abstrato, da gramática para o discurso: cópula $>$ marcador.

Resultante dessa trajetória, encontramos, na amostra estudada, a segunda maior ocorrência $(14,3 \%)$ do ser:

DOC: Fez só anotar?

INF:é, (T406-108-LFF)

b) Marcador de foco

O ser com essa função é objeto de uma pesquisa em andamento em que temos como hipótese que a forma é que é resultante de dois tipos de mudança: semântica: com o uso, o verbo

Isso conforme Martellota et al.(1996), pois a aceitação do processo de discursivização implica conflito com a visäo de gramática alargada (Cf. TRAUGOTT, 1995). 
ser perde parte de sua transparência semântica, correspondendo a uma reaplicação do significado gramatical, mas ainda conserva suas propriedades verbais (modo, tempo e número); depois, passa por graus diferentes de cristalização ou neutralização das referências externas originalmente traduzidas, até se tornar, num grau máximo, uma fórmula, portanto, semanticamente opaco e formalmente invariável; e categorial: com o uso, o que se gramaticaliza por meio do processo de recategorização sintática: Categoria maior [Pronome (relativo)] > Categoria menor [Conjunção (integrante)]

Na amostra estudada, encontramos:

b.1) $\operatorname{Ser}(\ldots)$ que

$(+)$ onde é que fica esse Mercado dos Pião" $(+)$ (T123-043-LFF)

b.2) Construção ser

A construção ser como marcador de foco é uma forma resultante do apagamento do que da fórmula ser (...) que, própria de construções clivadas.

DOC: Escute, e me conta eh... qual é a matéria que você mais gosta?

INF: gosto mais é de: :: (+) Matemática, (Q424-065LFF) 
c) Ser preenchedor de pausa

Trata-se de um uso mais abstrato que tem a função de preencher o vazio causado por pausas no fluxo das informações no discurso. Estas hesitações visam a uma reorganização da linearidade da fala perdida por motivos diversos, como insegurança, reformulações ou falhas de memória. Essa função está relacionada diretamente ou indiretamente às preocupações do falante, no momento de processar a fala, referentes ao seu discurso e à recepção do ouvinte.

(16) e meu pai já se casou com (+) é (+) eu chamo ela tia Lúcia' sabe"(O085-014-LFF)

Conforme a amostra estudada, esse último bloco marca um ponto de alta abstração do percurso do ser em que ele perde suas restrições formais de verbo, assumindo restrições de caráter pragmático e discursivo que marcam relações entre os participantes ou entre os participantes e seu discurso.

\section{Considerações Finais}

A partir do levantamento das significações/funções do ser, acreditamos ter encontrado o caminho para explicar a natureza e as funções desse item lexical. Como se trata apenas de um estudo piloto, esses resultados parciais confirmam-nos a possibilidade de explicar alguns significados/funções por meio da abstração progressiva, ou seja, as unidades polissêmicas partem de um sentido mais concreto para um mais abstrato; e a inferência metonímica pode também explicar alguns usos, considerando os contextos sintáticos e interacionais. É nesse sentido que propomos a explicação desses usos/ funções a partir do paradigma da gramaticalização. 
Porém leva-nos a refletir sobre a noção de unidirecionalidade da mudança e/ou de categorias radiais, uma vez que o estudo de Figueiredo-Gomes (1999) constatou uma tendência de trajetória que encerraria o processo seqüencial cópula $>$ marcador de afirmação. Como explicar então a trajetória defendida por Castilho (1997): Verbo pleno $>$ Verbo funcional [cópula] $]^{10}>$ Verbo auxiliar ? E as unidades do Bloco I teriam uma seqüência única ESPAÇO > TEMPO > .... ou haveria seqüências distintas, de forma radial, para cada unidade?

Acreditamos que uma pesquisa, com um volume maior de dados, e de natureza pancrônica, possa fornecer subsídios para sustentarmos que o ser tem significado(s) sim, o que nos falta é traçar a trajetória de suas unidades polissêmicas.

\section{Referências}

ARAGÃO, M. S. \& SOARES, M. E. Projeto dialetos sociais cearenses: a linguagem falada em Fortaleza. Fortaleza: Mestrado em Lingüística e Ensino da Língua Portuguesa-UFC, 1996.

BORBA, F. S. Uma gramática de valências para o português. São Paulo: Ática, 1996.

BRÉAL, M. Ensaios de semântica. São Paulo: EDUC, 1992.

BRITO, M. E. D. Complementação verbal: estudo dos elementos nominais básicos do verbo do português. Dissertação (Mestrado), Pontifícia Universidade Católica do Rio de Janeiro, Rio de Janeiro, 1986.

BYBEE, J.et al The evolution of grammar: tense, aspect, and modality in the languages of the world. Chicago: University of Chicago Press, 1994.

Cf. Castilho (1997, p. 28) 
CAStilho, A. T. A Gramaticalização. Caderno de estudos linguiiśsticos e literários. Salvador: UFBA, 1997.

CHAFE, W. L. Significado e estrutura lingiiística. Rio de Janciro: Livros Técnicos e Científicos, 1979.

CROFT, W. \& CRUISE, D. A. Linguistics cognitive. Cambridge: Cambridge University Press, 2004.

DU BOIS, J. W. Competing Motivations. In: HAIMAN, J. (ed.). Iconicity in syntax. Amsterdan: John Benjamins Publishing Company, 1985. p.343-65.

DU BOIS, J. Competing motivations. In: R. TOMLIN. Coherence and Grounding in discourse. Amsterdam: Benjamins, 1987.

FIGUEIREDO-GOMES, J. B. Item lexical ser: a trajetória para a afirmação no dialeto de Fortaleza. Dissertação (Mestrado), Universidade Federal do Ceará, Fortaleza, 1999.

FILLMORE, C. The case for case reopened. In: COLE, P. \& SADOCK, J. M. Sintax and semantics. New York: Ademic Press, 1977.

FURTADO DA CUNHA, M. A. Gramaticalização dos mecanismos de negação em Natal. In MARTELOTTA, M. et alii. Gramaticalização no português: uma abordagem funcional. Rio de Janeiro: Tempo Brasileiro; UFRJ, Departamento de Lingüística e Filologia, 1996.

GIVÓN, T. Functionalism and grammar: a prospectus. Oregon: University of Oregon, 1991.

. Functionalism and grammar. Philadelphia: Benjamins, 1995.

GUÉRIOS, R. F. Mansur. Origem do verbo ser. Revista Lingnagem, (s.d.). p.9-22.

HEINE, B. et al Grammaticalization: a conceptual framework. Chicago: The University of Chicago Press, 1991. 
HOPPER, P. \& TRAUGOTT, E. C. Grammaticalization. Cambridge: Cambridge University Press, 1993.

JOHNSON, M. The body in the mind: the bodily basis of meaning, imagination and reason. Chigago: The University of Chicago Press, 1987.

LAKOFF, G. Women, fire and dangerous things: what categories reveal about mind. Chicago: The University of Chicago Press, 1980.

\& JOHNSON, M. Metaphors we live by. Chicago: The University of Chicago Press, 1987.

MARTELOTTA, M. E. et al. Gramaticalização no português: uma abordagem funcional. Rio de Janeiro: Tempo Brasileiro: UFRJ, Departamento de Linguística e Filologia, 1996.

MIRA MATEUS, M. H. et al. Gramática da lingua portuguesa. Coimbra: Almedina, 1983.

PEZATTI, E. G. A ordem de palavras em português: aspectos tipológicos e funcionais. Tese de Doutorado. UNESP. Araraquara-SP, 1992.

TRAUGOTT, E. C. The role of the development of discourse markers in a theory of grammatialization. Manchester : Stanford University, 1995.

. \& KÖNIG, E. The semantics-pragmatics of grammaticalization revisited. In TRAUGOTT, E. C. \& HEINE, B. Approaches to grammaticalization. Vol. I. Focus on theorical and methodological issues. Amsterdam: Benjamins, 1991.

SAID ALI, M. Gramática histórica da língua portuguesa. Rio de Janeiro: Acadêmica, 1966.

SILVEIRA, A. L. D. História do verbo ser: do latim ao português. Natal: Universitária, 1980. 
SWEETSER, E. From etymology to pragmatics: metaphorical and cultural aspects of semantic strcture. Cambridge: Cambridge University Press, 1990.

VILELA, M. Gramática de valências: teoria e aplicação. Coimbra: Almedina, 1992. 